\title{
MANEJO DE IRRIGAÇÃO E FERTILIZAÇÃO NITROGENADA PARA O FEIJOEIRO NA REGIÃO DOS CERRADOS ${ }^{1}$
}

\author{
ANTÔNIO FERNANDO GUERRA² ${ }^{2}$ DIJALMA BARBOSA DA SILVA ${ }^{3}$ e GUSTAVO COSTA RODRIGUES ${ }^{3}$
}

RESUMO - Este trabalho foi desenvolvido na área experimental da Embrapa-Centro de Pesquisa Agropecuária dos Cerrados (CPAC) com o objetivo de estudar os efeitos de diferentes regimes hídricos e de diferentes doses de $\mathrm{N}$ sobre a produtividade e componentes de produção de feijão Pérola (Phaseolus vulgaris $\mathrm{L}$.) cultivado após o milho, na região de cerrado. As aplicações de água foram feitas quando a tensão de água no solo, medida a $10 \mathrm{~cm}$ de profundidade, atingia valores de 41, 55, 75 e $300 \mathrm{kPa}$. As doses de $\mathrm{N}$ testadas foram: $0,40,80 \mathrm{e} 160 \mathrm{~kg} / \mathrm{ha}$. As doses foram parceladas em duas aplicações, a saber: a metade, aplicada por ocasião da emergência das plântulas, e o restante, no início do estádio de florescimento da cultura. A máxima produtividade foi obtida com as irrigações quando a tensão de água no solo era de $41 \mathrm{kPa}$, medida a $10 \mathrm{~cm}$ de profundidade. As doses de $\mathrm{N}$ que propiciaram as máximas produtividades variaram com a tensão de água no solo utilizada para o controle da irrigação. A quantidade de água aplicada para uma produtividade superior a $4.800 \mathrm{~kg} / \mathrm{ha}$ foi em torno de $450 \mathrm{~mm}$. O valor da relação entre a produtividade e a lâmina de água aplicada aumentou com o aumento da tensão de água no solo e das doses de $\mathrm{N}$.

Termos para indexação: Phaseolus vulgaris, relação planta-água, rendimento de culturas, níveis de irrigação, balanço hídrico do solo, nitrogênio.

\section{IRRIGATION TIMING AND NITROGEN FERTILIZATION FOR COMMON BEAN CROP IN THE CERRADO REGION}

\begin{abstract}
This study was carried out in the experimental field of the Embrapa-Centro de Pesquisa Agropecuária dos Cerrados (CPAC) to determine the irrigation timing and the nitrogen amounts for common bean crop (Phaseolus vulgaris L.), cultivated after corn, in the cerrado region. Water was applied when soil-water tension, measured at a depth of $10 \mathrm{~cm}$ reached values of $41,55,75$ and $300 \mathrm{kPa}$. The nitrogen doses were splited in two applications. Half doses was applied just after germination and the other half at the initial flowering stage. The highest yield was obtained with irrigation at $41 \mathrm{kPa}$, measured at a depth of $10 \mathrm{~cm}$. In relation to nitrogen doses, maximum yield was attained with variable soil water tension value used to control water application. The total amount of water applied to common bean crop for a yield over $4,800 \mathrm{~kg} / \mathrm{ha}$ was approximately $450 \mathrm{~mm}$. The value of the relationship between yield and applied water increased as soil water tension and nitrogen doses increased.
\end{abstract}

Index terms: Phaseolus vulgaris, plant water relations, crop yield, irrigation rates, soil water balance, nitrogen.

\section{INTRODUÇÃO}

Na região do cerrado o cultivo do feijoeiro irrigado atinge anualmente uma área superior a $100 \mathrm{mil}$

\footnotetext{
${ }^{1}$ Aceito para publicação em 30 de dezembro de 1999.

${ }^{2}$ Eng. Agríc., Ph.D., Embrapa-Centro de Pesquisa Agropecuária dos Cerrados (CPAC), Caixa Postal 08233, CEP 73301-970 Planaltina, DF. E-mail: guerra@cpac.embrapa.br

${ }^{3}$ Eng. Agrôn., M.Sc., Embrapa-CPAC.
}

hectares. Isso ocorre porque o feijoeiro é, normalmente, a cultura anual de maior valor econômico. Nessas áreas irrigadas o feijoeiro tem condições de ser cultivado com alto nível tecnológico, pois a irrigação permite que o plantio seja feito em épocas adequadas e garante o fornecimento de água para que as plantas demonstrem o seu potencial produtivo. Entretanto, apesar de existirem condições propícias ao cultivo do feijoeiro, as produtividades obtidas nas lavouras são da ordem de $2.400 \mathrm{~kg} / \mathrm{ha}$ en- 
quanto o potencial produtivo das cultivares existentes é superior a $4.000 \mathrm{~kg} / \mathrm{ha}$.

Entre os fatores que têm contribuído para que os produtores não atinjam altas produtividades de feijão nessas áreas estão a utilização de equipamentos de irrigação desajustados, funcionando com baixa uniformidade de distribuição de água, bem como o cultivo sucessivo dessa leguminosa, que favorece o desenvolvimento de doenças causadas por fungos do solo ou do sistema radicular, como, por exemplo, o mofo-branco, a fusariose e a rizoctoniose.

Segundo Curl (1963), a prática de rotação de culturas de gramíneas-leguminosas e o manejo adequado do solo e da água são indispensáveis para reduzir o potencial de inóculo de doenças e assim manter o potencial produtivo das áreas sob irrigação.

A adubação nitrogenada inadequada é outro fator que muitas vezes determina o insucesso no cultivo do feijoeiro. Enquanto alguns produtores continuam aplicando doses excessivas de $\mathrm{N}$, outros aplicam quantidades insuficientes desse elemento, limitando a produtividade da lavoura mesmo que outros fatores de produção sejam otimizados. Carvalho et al. (1992) recomendam a dose de $\mathrm{N}$ de $90 \mathrm{~kg} / \mathrm{ha}$ para obtenção da máxima produtividade. Por outro lado, Silveira \& Damasceno (1993) recomendam apenas $72 \mathrm{~kg} / \mathrm{ha}$ de $\mathrm{N}$ para maximizar a produtividade do feijoeiro. Segundo Calheiros et al. (1996), as maiores rendas líquidas de feijão resultam da aplicação de $90 \mathrm{~kg} / \mathrm{ha}$.

Com relação às necessidades hídricas do feijoeiro, Macedo Júnior et al. (1994) verificaram que as maiores produtividades ocorreram quando a disponibilidade de água para as plantas era máxima. Guimarães et al. (1996a, 1996b) definem como irrigação adequada ao feijoeiro uma tensão de $35 \mathrm{kPa}$ medida a $15 \mathrm{~cm}$ de profundidade. Chagas et al. (1994) verificaram que a maior eficiência de uso de água para o feijoeiro ocorreu com a aplicação de baixas lâminas de irrigação.

Embora os insumos água e N estejam intimamente relacionados, pois o $\mathrm{N}$ entra em contato com as raízes das plantas principalmente pelo processo de fluxo de massa, a maioria dos trabalhos de pesquisa citados os tem estudado separadamente.

O objetivo deste trabalho foi estudar os efeitos de diferentes regimes hídricos e doses de $\mathrm{N}$ sobre a produtividade e componentes de produção do feijão Pérola, na região dos cerrados.

\section{MATERIAL E MÉTODOS}

O experimento foi conduzido no campo experimental da Embrapa-Centro de Pesquisa Agropecuária dos Cerrados (CPAC), em Planaltina, DF (latitude: $15^{\circ} 35^{\prime} 30^{\prime \prime} \mathrm{S}$, longitude: $47^{\circ} 42^{\prime} 30^{\prime \prime} \mathrm{W}$, e altitude: $998 \mathrm{~m}$ ), no período de junho a setembro de 1996.

O solo da área experimental foi classificado como um Latossolo Vermelho-Escuro, fase argilosa. As características físicas e químicas do solo estão apresentados em Guerra (1994).

Foi utilizado o feijão (Phaseolus vulgaris L.), cultivar Pérola, desenvolvida pela Embrapa-Centro Nacional de Pesquisa de Arroz e Feijão (CNPAF).

O milho foi cultivado anteriormente na área experimental, durante a estação chuvosa. Depois de colhido, os restos culturais foram incorporados ao solo.

As doses de fósforo $\left(\mathrm{P}_{2} \mathrm{O}_{5}\right)$ e potássio $\left(\mathrm{K}_{2} \mathrm{O}\right)$ foram determinadas com base nos resultados da análise química do solo. Foram aplicados, em toda a área experimental, $450 \mathrm{~kg} / \mathrm{ha} \mathrm{da}$ formulação $0-20-20$ e $40 \mathrm{~kg} / \mathrm{ha} \mathrm{de}$ FTE BR-10. Por se tratar de um ensaio com $\mathrm{N}$, este não foi aplicado na adubação de base

A semeadura do feijão nas parcelas experimentais foi realizada manualmente, no dia 10/6/96, em sulcos, com espaços entre si de $50 \mathrm{~cm}$. Foram utilizadas 14 sementes viáveis por metro de sulco. Após os estádios de desenvolvimento iniciais, contou-se o número de plantas e procedeu-se a um desbaste, para homogeneizar a população de plantas para a condição da subparcela com menor número de plantas, ou seja, 232.800 plantas por hectare

O delineamento experimental utilizado foi o de blocos ao acaso, em parcelas subdivididas, com três repetições. A parcela apresentou dimensões de $4 \mathrm{~m} \times 20 \mathrm{~m}$, e a subparcela, de $4 \mathrm{~m}$ x $5 \mathrm{~m}$, ficando como área útil $13,5 \mathrm{~m}^{2} \mathrm{da}$ parte central da subparcela. Como tratamentos principais, foram testados quatro níveis de tensão de água no solo, previamente definidos como 33, 50, 70 e $300 \mathrm{kPa}$. Nas subparcelas, foram testadas quatro doses de nitrogênio ou seja: $0,40,80$ e $160 \mathrm{~kg} /$ ha de $\mathrm{N}$, na forma de uréia. $\mathrm{ON}$ foi aplicado manualmente, em duas vezes: metade, por ocasião da emergência das plântulas, e o restante, no início do florescimento da cultura.

Foi utilizado um sistema de irrigação por microaspersão, com espaçamento de $4 \mathrm{mx} 4 \mathrm{~m}$, que apresentou um coeficiente de uniformidade de Christiansen (CUC) de 90\% e lâmina de irrigação de $54,7 \mathrm{~mm} / \mathrm{h}$. 
O manejo das irrigações foi monitorado por tensiômetros de mercúrio e blocos de gesso. Em cada tratamento, instalou-se uma bateria, com seis tensiômetros de mercúrio e seis blocos de gesso, na linha da cultura, nas profundidades de 10, 20, 30, 40, 60 e $80 \mathrm{~cm}$.

As leituras nos tensiômetros e nos blocos de gesso foram realizadas diariamente, a partir das $8 \mathrm{~h}$, durante todo o ciclo da cultura. O momento de irrigar foi determinado quando a tensão de água no solo, na profundidade de $10 \mathrm{~cm}$, atingia valores aproximadamente iguais aos preestabelecidos $(33,50,70$ e $300 \mathrm{kPa})$. Em seguida, a partir das leituras de tensão de água no solo nas profundidades de 10, 20 e $30 \mathrm{~cm}$, calculou-se a lâmina d'água a ser aplicada por irrigação, por tratamento, baseado no déficit hídrico do perfil de solo de $35 \mathrm{~cm}$. O perfil de $35 \mathrm{~cm}$ foi estabelecido em razão das características do sistema radicular do feijão, conforme indicado por Pires et al. (1991) e Stone \& Pereira (1994). No cálculo da lâmina d'água, para tensões até $70 \mathrm{kPa}$, foram utilizadas leituras de tensiômetros, e nas demais, leituras de blocos de gesso medidas por um ohmímetro.

A curva característica de retenção de água no solo e a curva de calibração dos blocos de gesso estão apresentadas em Guerra (1995).

Os tensiômetros, antes de levados ao campo, foram cuidadosamente testados em laboratório, para verificar a ocorrência de possíveis vazamentos.

As aplicações de água foram suspensas quando as vagens do terço médio das plantas mudaram de cor. Ao apresentarem um amarelecimento intenso, as plantas foram arrancadas e deixadas expostas ao sol para perderem umidade. Quando os grãos estavam com umidade próximo a $14 \%$, foi feita a colheita

A colheita foi feita a máquina. A área colhida em cada tratamento foi de $13,5 \mathrm{~m}^{2}$ (3 $\mathrm{m} \mathrm{x} \mathrm{4,5} \mathrm{m)} \mathrm{(subparcela} \mathrm{útil),}$ eliminando-se uma linha de cultura na parte inferior e na parte superior, e $25 \mathrm{~cm}$ em cada lateral, da subparcela experimental $(5 \mathrm{mx} 4 \mathrm{~m})$.

Foram determinados os seguintes componentes de produção, em cada subparcela: número de plantas por metro quadrado, avaliado com a contagem de todas as plantas da subparcela útil; número de grãos por planta, estimado a partir da contagem de três linhas centrais da subparcela útil; número de vagens por planta, estimado a partir da contagem das vagens de três linhas centrais da subparcela útil; massa de 100 grãos, avaliada em 10 amostras de 100 grãos de cada subparcela útil; rendimento de grãos, avaliado após a colheita de toda a subparcela útil; porcentagem de $\mathrm{N}$ nos grãos, avaliado em laboratório a partir de três amostras de grãos de cada subparcela útil; relação entre a produtividade e a lâmina total aplicada em cada regime hídrico

\section{RESULTADOS E DISCUSSÃo}

Durante o período experimental foi possível aplicar todos os tratamentos previstos, uma vez que só ocorreram chuvas de baixa intensidade e curta duração no final do ciclo da cultura.

As tensões de água no solo, medidas na linha de plantio a $10 \mathrm{~cm}$ de profundidade, durante todo o ciclo da cultura resultaram em média nos valores de 41 , 55,75 e $300 \mathrm{kPa}$.

Pela Fig. 1, verifica-se que a produtividade do feijão aumentou com o decréscimo da tensão de água no solo, para todas as doses de N. Os resultados indicam que existe uma probabilidade superior a $95 \%$ de que esses aumentos de produtividade sejam explicados pelas variações da tensão de água no solo. O máximo rendimento ocorreu quando as irrigações foram feitas a $41 \mathrm{kPa}$, e com aplicação de $160 \mathrm{~kg} / \mathrm{ha}$ de N. Macedo Júnior et al. (1994) obtiveram o máximo rendimento de feijão com a maior disponibilidade de água para as plantas, ou seja, com a menor tensão de água no solo testada. Quando as irrigações foram

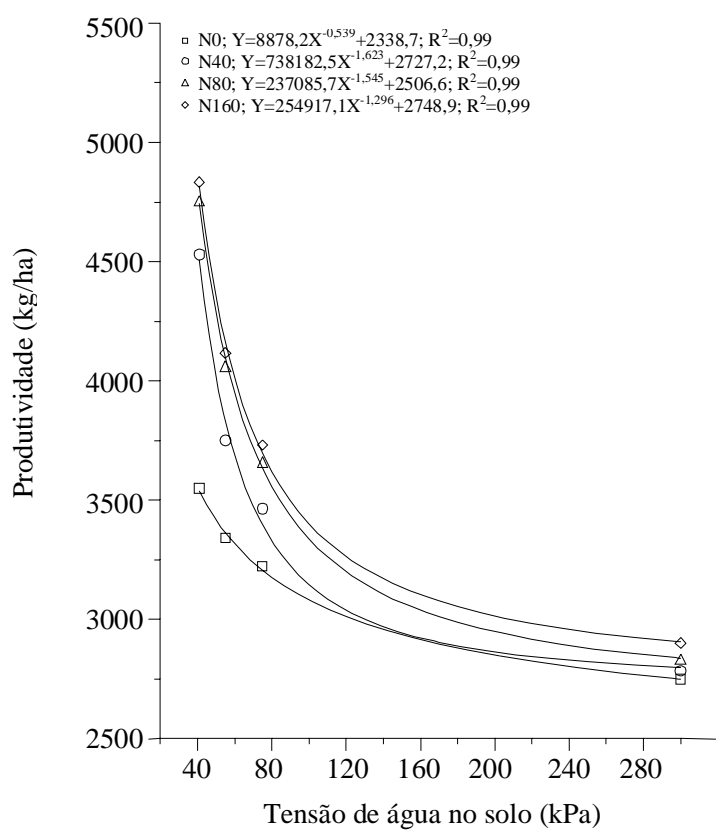

FIG. 1. Produtividade do feijoeiro em relação à tensão de água no solo nas doses de $\mathrm{N}$ de zero (N0) a $160 \mathrm{~kg} / \mathrm{ha}(\mathrm{N} 160)$.

Pesq. agropec. bras., Brasília, v.35, n.6, p.1229-1236, jun. 2000 
feitas sob tensão de água no solo de $300 \mathrm{kPa}$, a produtividade foi reduzida drasticamente em todas as doses de $\mathrm{N}$ testadas. Isso ocorreu porque nesse regime hídrico as plantas ficaram sujeitas a um estresse hídrico severo, o qual, certamente, comprometeu também a absorção de $\mathrm{N}$ pelas plantas.

Pela Fig. 2, observa-se que nos tratamentos irrigados a 41, 55 e $75 \mathrm{kPa}$, a produtividade teve seus maiores incrementos quando a dose de $\mathrm{N}$ variou de zero a $40 \mathrm{~kg} / \mathrm{ha}$. Essa taxa de incremento de produtividade decresceu à medida que foram aumentadas as doses de $\mathrm{N}$ de 40 para $80 \mathrm{~kg} / \mathrm{ha}$ e de 80 para $160 \mathrm{~kg} / \mathrm{ha}$. No tratamento irrigado a $300 \mathrm{kPa}$, o efeito das doses de $\mathrm{N}$ sobre a produtividade foi menor $\mathrm{e}$ linear, o que sugere que nessa condição de estresse hídrico severo, tanto a liberação de $\mathrm{N}$ natural do solo quanto a absorção de $\mathrm{N}$ pelas plantas foram prejudicadas. Guimarães et al. (1996b) definem como irrigação adequada para o feijão uma tensão inferior a $35 \mathrm{kPa}$ medida a $15 \mathrm{~cm}$ de profundidade. No trabalho desses autores, exceto na dose zero de $\mathrm{N}$, as maiores produtividades foram obtidas quando as irrigações

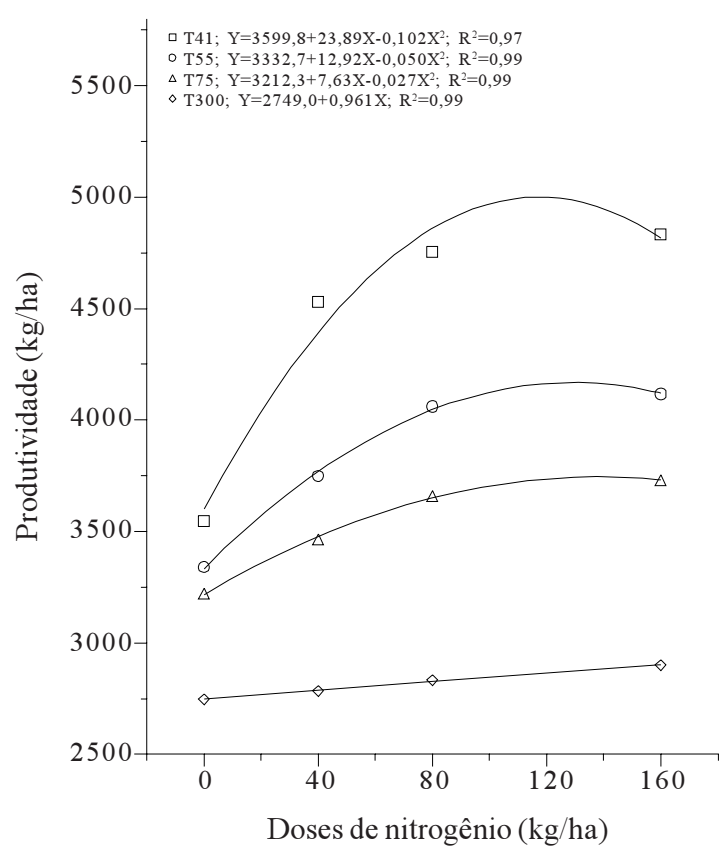

FIG. 2. Produtividade do feijoeiro em relação às doses de $\mathbf{N}$ nas tensões de água no solo de 41 (T41) a $300 \mathrm{kPa}(\mathrm{T} 300)$. foram feitas a $41 \mathrm{kPa}$, ou seja, na menor tensão de água testada. Isso demonstra que o feijão, quando cultivado com um padrão de tecnologia para obtenção de altas produtividades, é uma planta exigente em água.

Calheiros et al. (1996), buscando estabelecer estratégias ótimas de irrigação para a cultura de feijão em relação à renda líquida do produto, conclui que nas condições em que a água é limitante, a irrigação com déficit pode ser uma excelente estratégia no planejamento da irrigação do feijoeiro. Os autores indicam, também, que a dose de $90 \mathrm{~kg} / \mathrm{ha}$ de $\mathrm{N}$ proporcionou as maiores rendas líquidas do feijão.

Carvalho et al. (1992) recomendam a dose de $90 \mathrm{~kg} / \mathrm{ha}$, metade aplicada na pré-floração e o restante na floração plena. Silveira \& Damasceno (1993) indicam que a produtividade máxima do feijão é obtida com uma dose de $72 \mathrm{~kg} / \mathrm{ha}$ de N. Se observadas as diferenças de produtividade obtidas nos diferentes trabalhos de pesquisa, verificamos uma semelhança na magnitude da dose de $\mathrm{N}$, que resultou em altas produtividades do feijão, o que permite inferir que não é necessário doses excessivas de $\mathrm{N}$ mesmo para obtenção de produtividades superiores a $4.500 \mathrm{~kg} / \mathrm{ha}$ de grãos.

Pela Fig. 3, verifica-se que o número de vagens por planta aumentou quando foram elevadas as doses de $\mathrm{N}$ e quando foram reduzidas as tensões de água no solo usadas para monitorar as irrigações. $\mathrm{O}$ máximo número de vagens por planta foi observado nos tratamentos irrigados a menores tensões de água no solo e maiores doses de $\mathrm{N}$, indicando, assim, que para obter elevados números de vagens é necessário aplicar água e $\mathrm{N}$, de forma a obter também um maior desenvolvimento vegetativo das plantas. Macedo Júnior et al. (1994) relatam que obtiveram o máximo número de vagens por planta com irrigação a $10 \mathrm{kPa}$. Nos tratamentos irrigados a 41 e $55 \mathrm{kPa}, \mathrm{o}$ número de vagens por planta variou de, aproximadamente, 11 para 14 quando as doses de $\mathrm{N}$ variaram de zero a $160 \mathrm{~kg} / \mathrm{ha}$. Por outro lado, quando as irrigações foram feitas a uma tensão de água no solo de $75 \mathrm{kPa}$, no qual as plantas ficaram sujeitas a um estresse hídrico moderado, o número de vagens por planta variou entre 10 e 11,5. Isso indica que a condição de estresse hídrico moderado é suficiente para causar uma redução significativa do número de va- 
gens por planta. Finalmente, quando as irrigações foram feitas a uma tensão de água no solo de $300 \mathrm{kPa}$, o número de vagens por planta teve apenas um pequeno acréscimo de 9,5 para 10,5 , quando a dose de $\mathrm{N}$ passou de zero para $160 \mathrm{~kg} / \mathrm{ha}$. Também Guimarães et al. (1996b) verificaram reduções do número de vagens da ordem de $13,8 \%$ e $38,9 \%$ em condições de estresse hídrico moderado e severo, respectivamente. Com relação ao N, Silveira \& Damasceno (1993) obtiveram aumento significativo do número de vagens por planta quando se elevou as doses desse nutriente para a cultura do feijoeiro. Esses resultados indicam que tanto a irrigação quanto a fertilização nitrogenada devem ser feitas de forma adequada para garantir um maior número de vagens por planta de feijão.

Pela Fig. 4, verifica-se que o número de grãos por planta é definido mais pelos regimes hídricos impostos do que pelas doses de $\mathrm{N}$ aplicadas. Isso provavelmente ocorre porque o desenvolvimento das plan- tas é influenciado principalmente pelos regimes hídricos impostos. Entretanto, as respostas do número de grãos por planta à aplicação de $\mathrm{N}$ são maiores quando as irrigações são feitas a tensões mais baixas de água no solo. Observa-se, pela Fig. 4, que na condição de estresse hídrico severo, irrigação a $300 \mathrm{kPa}$, o aumento do número de grãos por planta quando a dose de $\mathrm{N}$ foi elevada de zero para $160 \mathrm{~kg} / \mathrm{ha}$ foi irrisório. Por outro lado, se considerada apenas a dose de $\mathrm{N}$ de $80 \mathrm{~kg} / \mathrm{ha}$, a qual resultou em rendimentos elevados, o número de grãos por planta variou de 40 para 72 quando as irrigações foram feitas a 300 e $41 \mathrm{kPa}$, respectivamente.

Pela Fig. 5, verifica-se que a massa de 100 grãos aumentou tanto com as doses de $\mathrm{N}$ quanto com os níveis de tensão de água no solo usados como critério para as aplicações de água. Mas esse componente de produtividade é mais afetado pelos regimes hídricos do que pelas doses de N. Nos tratamentos irrigados a 41 e $55 \mathrm{kPa}$, a massa de 100 grãos variou

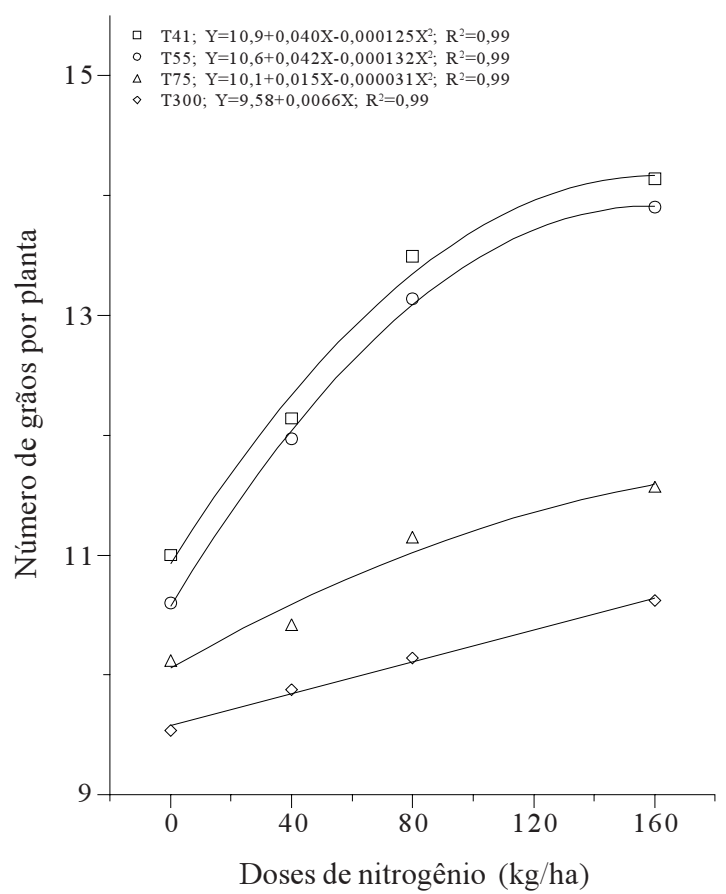

FIG. 3. Número de vagens por planta de feijão em relação às doses de $\mathrm{N}$ nas tensões de água no solo de 41 (T41) a $300 \mathrm{kPa}$ (T300).

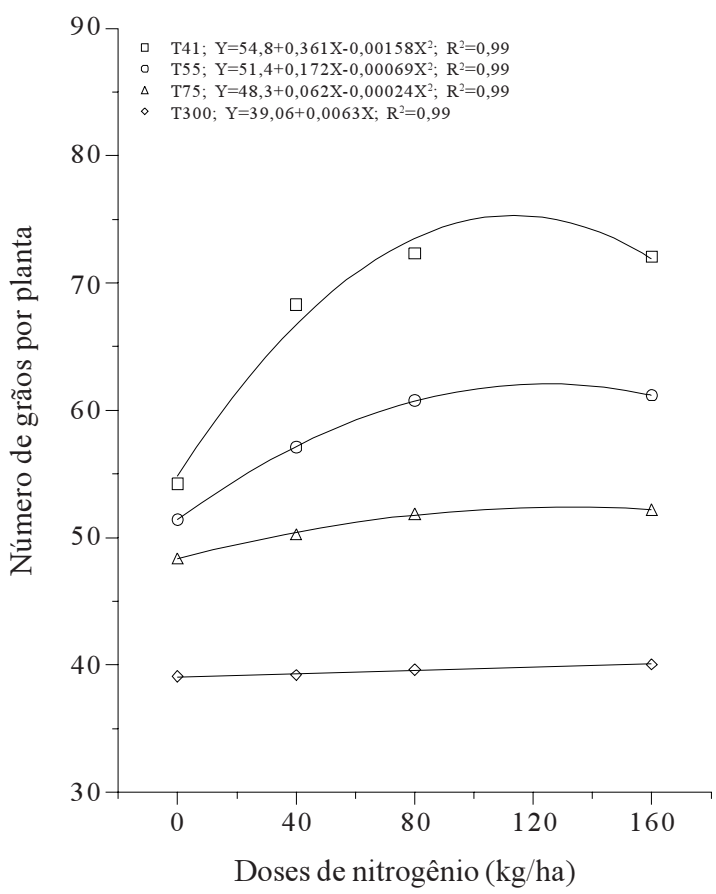

FIG. 4. Número de grãos por planta em relação às doses de $\mathrm{N}$ nas tensões de água no solo de 41 (T41) a $300 \mathrm{kPa}(\mathrm{T} 300)$.

Pesq. agropec. bras., Brasília, v.35, n.6, p.1229-1236, jun. 2000 
de $28 \mathrm{~g}$ na dose zero de $\mathrm{N}$ para $28,5 \mathrm{~g}$ na dose de $160 \mathrm{~kg} / \mathrm{ha}$ de N. Já no tratamento irrigado a $75 \mathrm{kPa}$, a massa de 100 grãos variou de 28,6 g na dose zero de $\mathrm{N}$ para $30,7 \mathrm{~g}$ na dose de $160 \mathrm{~kg} / \mathrm{ha}$ de $\mathrm{N}$. Neste nível de tensão de água no solo houve a maior variação da massa de 100 grãos. Silveira \& Damasceno (1993), entretanto, obtiveram redução da massa de 100 grãos com o aumento das doses de N. No tratamento irrigado a $300 \mathrm{kPa}$, o aumento da massa de 100 grãos foi linear e de magnitude relativamente pequena.

Ao contrário dos resultados obtidos neste trabalho, Guimarães et al. (1996b) verificaram uma redução da massa de 100 grãos de feijão em condição de estresse hídrico. Na condição do presente trabalho, o tratamento com estresse hídrico severo foi aplicado durante todo o ciclo da cultura determinando um ajustamento do desenvolvimento das plantas para essa condição hídrica. Nessa situação, as plantas desenvolvem-se menos, e produzem menos vagens e grãos para garantir um enchimento adequado dos grãos.

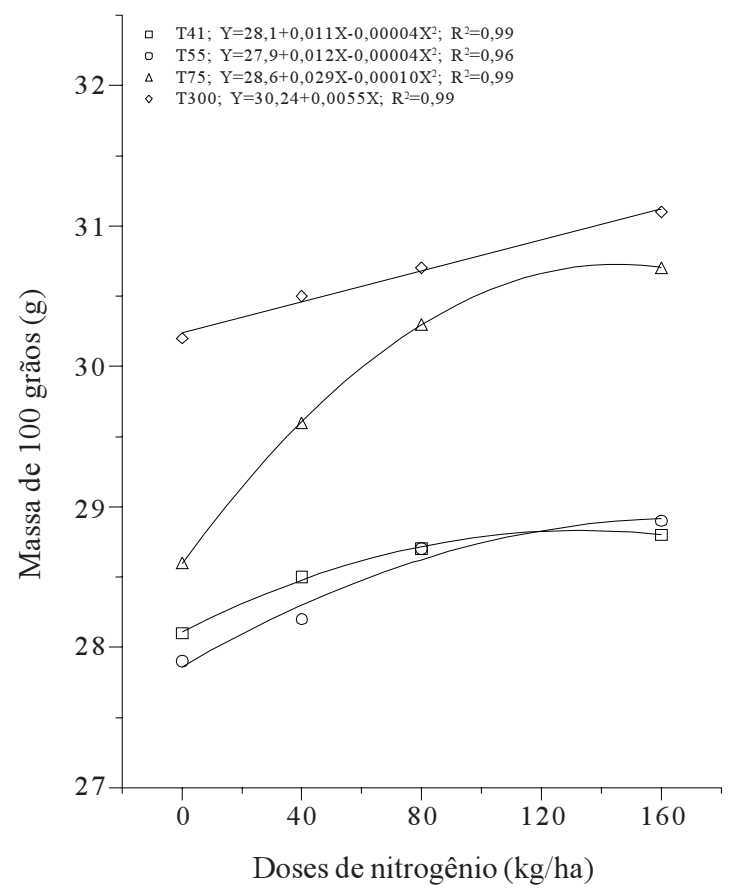

FIG. 5. Massa de 100 grãos de feijão em relação às doses de $\mathrm{N}$ nas tensões de água no solo de 41 (T41) a 300 kPa (T300).
A porcentagem de $\mathrm{N}$ média dos grãos de feijão foi $3,14 \%$; nem os regimes hídricos impostos nem as doses de $\mathrm{N}$ aplicadas causaram variações significativas nessa porcentagem. Silva et al. (1989) relatam que a proteína dos grãos de feijão foi maior quando utilizaram maiores doses de $\mathrm{N}$.

Pozzebon et al. (1996) verificaram uma menor concentração de $\mathrm{N}$ nos grãos nos tratamentos irrigados em comparação com os não irrigados. Em cultivos sem irrigação as plantas podem ter condições de umidade satisfatórias nos estádios de desenvolvimento iniciais e estresse hídrico em estádios de desenvolvimento mais adiantados, o que prejudica o enchimento de grãos e faz com que a porcentagem de $\mathrm{N}$ no grãos seja elevada.

Pessoa et al. (1996) relatam concentrações de N nos grãos de feijão de $3,47 \%$. Esse valor é superior aos encontrados no presente trabalho, o que pode ser devido a diferenças entre cultivares.

Verifica-se, pela Fig. 6, que, quando as irrigações foram feitas a $41 \mathrm{kPa}$, foram aplicados $450 \mathrm{~mm}$ duran-

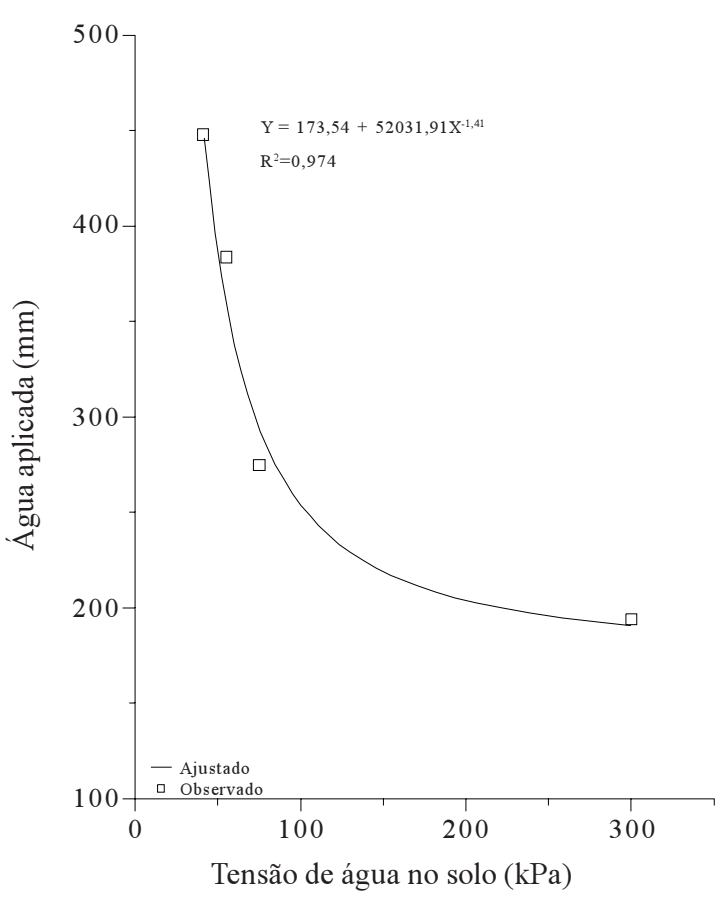

FIG. 6. Lâmina de água aplicada no feijoeiro em relação a quatro regimes hídricos. 
te o ciclo do feijoeiro. À medida que se utilizaram maiores tensões de água nos solo como critério para as aplicações de água, houve uma redução da lâmina total de água aplicada na cultura, devido a um menor desenvolvimento vegetativo do feijoeiro.

Pelas equações de ajuste da Fig. 1 e da Fig. 6, calculou-se a produtividade obtida em cada nível de tensão de água no solo e em cada dose de N; calculou-se também a lâmina de água aplicada em cada regime hídrico. Posteriormente, calculou-se a relação entre a produtividade e a lâmina de água aplicada, em termos de quilogramas de grãos por milímetro de água aplicada, os quais estão apresentados na Fig. 7. Os resultados indicam que a maior massa de grãos por milímetro de água aplicada ocorreu no tratamento irrigado a $300 \mathrm{kPa}$, com aplicação de $160 \mathrm{~kg} / \mathrm{ha}$ de N. Por outro lado, a menor massa de grãos por milímetro de água aplicada ocorreu na dose zero de $\mathrm{N}$ e irrigação a $41 \mathrm{kPa}$. Considerando o tratamento irrigado a $41 \mathrm{kPa}$ e com dose de $80 \mathrm{~kg} / \mathrm{ha}$ de N, o qual

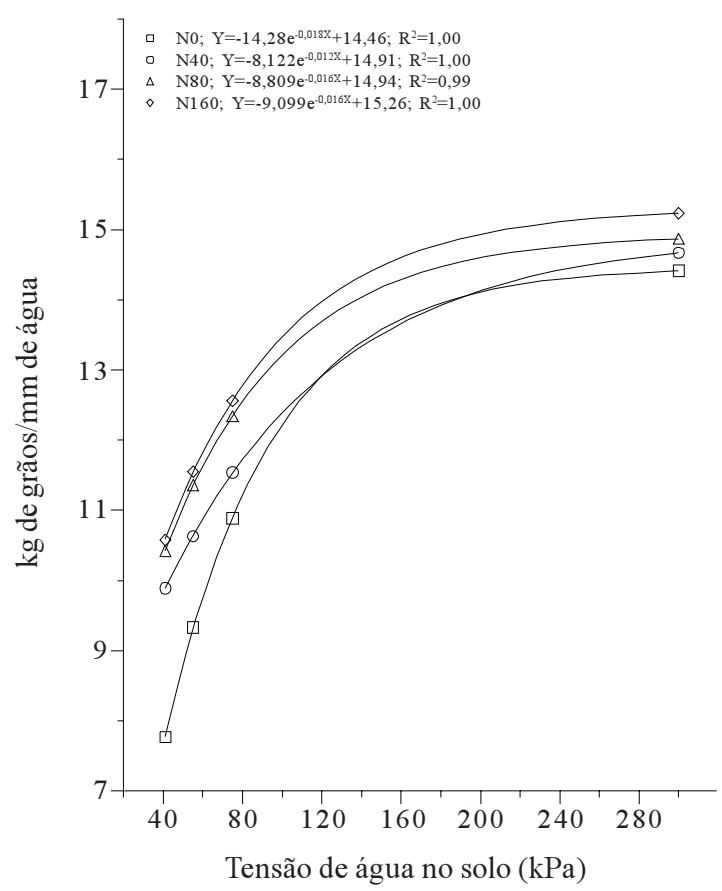

FIG. 7. Produtividade e lâmina de água aplicada no feijoeiro, com relação a quatro regimes hídricos nas doses de $\mathrm{N}$ de zero (NO) a $160 \mathrm{~kg} / \mathrm{ha}$ (N160). resultou em alta produtividade, a massa de grãos por milímetro de água aplicada foi de aproximadamente $10,4 \mathrm{~kg} / \mathrm{mm}$. Analisando os resultados de produtividade em relação às lâminas de água aplicadas no trabalho desenvolvido por Chagas et al. (1994) verifica-se que as maiores eficiências da água aplicada foram obtidas também nos tratamentos que receberam menores lâminas totais de irrigação. Entretanto, embora esse seja um dos parâmetros utilizados para definir as estratégias de aplicação de água para as lavouras, deve-se considerar as condições limitantes da produtividade e o preço do produto para se estabelecer o regime hídrico a ser imposto na lavoura, pois obter a máxima relação entre produtividade e lâmina de água aplicada quase nunca é a melhor opção econômica.

\section{CONCLUSÕES}

1. Os mais altos rendimentos da cultura de feijão resultam de irrigações a menores tensões de água no solo e aplicação de doses elevadas de nitrogênio.

2. O número de vagens por planta, número de grãos por planta e massa de 100 grãos variam em decorrência de mudança do regime hídrico e da dose de nitrogênio.

3. A porcentagem de nitrogênio dos grãos não é alterada pelos regimes hídricos nem pelas doses de nitrogênio.

4. A quantidade de água aplicada decresce com o aumento das tensões de água no solo.

5. O valor da relação entre produtividade e lâmina de água aplicada aumenta com o aumento das tensões de água no solo e das doses de nitrogênio.

\section{REFERÊNCIAS}

CALHEIROS, C.B.M.; QUEIROZ, J.E.; FRIZZONE, J.A.; PESSOA, P.C.S. Estratégias ótimas de irrigação do feijoeiro: água como fator limitante da produção. Pesquisa Agropecuária Brasileira, Brasília, v.31, n.7, p.509-515, jul. 1996.

CARVALHO, A.M. de; SILVA, A.M. da; COSTA, E.F. da; COUTO, L. Influência da fertirrigação no rendimento de grãos e componentes de produção do feijoeiro comum (Phaseolus vulgaris L.) cv. Carioca. Ciência e Prática, Lavras, v.16, n.4, p.503-511, 1992

Pesq. agropec. bras., Brasília, v.35, n.6, p.1229-1236, jun. 2000 
CHAGAS, J.M.; GOMES, J.M.; VIEIRA, C.; ARAÚJO, G.A. de A. Efeitos de quantidades de água sobre a cultura do feijão (Phaseolus vulgaris L.), em quatro sistemas de manejo de solo. Revista Ceres, Viçosa, v.41, n.238, p.641-650, 1994

CURL, E.A. Control of plant diseases by plant rotation. Botanical Review, New York, v.29, n.4, p.413-477, 1963.

GUERRA,A.F. Manejo de irrigação da cevada sob condições de cerrado visando o potencial de produção. Pesquisa Agropecuária Brasileira, Brasília, v.29, n.7, p.1111-1118, jul. 1994.

GUERRA, A.F. Tensão de água no solo: efeito sobre a produtividade e qualidade dos grãos de cevada. Pesquisa Agropecuária Brasileira, Brasília, v.30, n.2, p. 245-254, fev. 1995.

GUIMARÃES, C.M.; BRUNINI, O.; STONE, L.A. Adaptação do feijoeiro à seca. I. Densidade e eficiência radicular. Pesquisa Agropecuária Brasileira, Brasília, v.31, n.6, p.393-399, jun. 1996a.

GUIMARÃES, C.M.; STONE, L.A.; BRUNINI, O Adaptação do feijoeiro (Phaseolus vulgaris L.) à seca. II. Produtividade e componentes agronômicos. Pesquisa Agropecuária Brasileira, Brasília, v.31, n.7, p.481-488, jul. 1996b.

MACEDO JÚNIOR, E.K.; FARIA, M.A. de; SOARES, A.M. Produção do feijoeiro (Phaseolus vulgaris L.) submetido a cinco níveis de tensão de água no solo. Ciência e Prática, Lavras, v.18, n.4, p.438-444, 1994.
PESSOA, A.C. dos S.; KELLING, C.R.S.; POZZEBON, E.J.; KÖNIG, O. Concentração e acumulação de nitrogênio, fósforo e potássio pelo feijoeiro cultivado sob diferentes níveis de irrigação. Ciência Rural, Santa Maria, v.26, n.1, p.69-74, 1996.

PIRES, R.C. de M.; ARRUDA, F.B.; FUGIWARA, N.; SAKAI, E.; BORTOLETTO, N. Profundidade do sistema radicular das culturas de feijão e trigo sob pivô central. Bragantia, Campinas, v.50, n.1, p.153162,1991

POZZEBON, E.J.; CARLESSO, R.; KELLING, C.; PESSOA, A.C. dos S.; KÖNIG, O. Concentração de nitrogênio, fósforo e potássio na parte aérea do feijoeiro em resposta à irrigação, fertirrigação e micronutrientes. Ciência Rural, Santa Maria, v.26, n.2, p.191-196, 1996

SILVA, A.J. da; RAMALHO, M.A.P.; GUEDES, G.A. de A.; VALE, F.R. do. Resposta de cultivares de feijão (Phaseolus vulgaris L.) à adubação nitrogenada. I Produção de grãos e seus componentes. Ciência e Prática, Lavras, v.13, n.3, p.348-355, 1989.

SILVEIRA, P.M. da; DAMASCENO, M.A. Doses e parcelamento de $\mathrm{K}$ e $\mathrm{N}$ na cultura do feijoeiro irrigado. Pesquisa Agropecuária Brasileira, Brasília, v.28, n.11, p.1269-1276, nov. 1993.

STONE, L.F.; PEREIRA, A.L. Sucessão arroz-feijão irrigados por aspersão: efeitos de espaçamento entre linhas, adubação e cultivar no crescimento, desenvolvimento radicular e consumo de água do feijoeiro. Pesquisa Agropecuária Brasileira, Brasília, v.29, n.6, p.939-954, jun. 1994 